Gina Ziebell

\title{
Why Does the One Only Exist in Cyberspace? Obsolescence of the Body, Construction of a Virtual Subject and the Question of Control in The Matrix
}

\section{Introduction: Why Identity Matters in Virtual Reality}

Not so long ago, the future of the science fiction film was considered bleak by some of the most important scholars in this area (Sobchack qtd. in Landon xxii). Even cyberpunk, celebrated by some for its unprecedented engagement with postmodern issues (Barnett 6; Landon xxiv) and seen critically by others (Bould 228), had lost much of its creativity. Barnett summarizes that cyberpunk works had become "restrained, commercialized, and mimetic" (360) since, according to Fredric Jameson, it had turned into "mere 'realism' and an outright representation of the present." Jameson continues his criticism with more detail, pointing to the limitations of a representative form in a genre that lives from its innovations (qtd. in Barnett 361). "Based on this criticism," Barnett concludes, "if the cyberpunk aesthetic is to be resuscitated, it must regain its Bohemian edge, return to its underground roots and present a more accurate depiction of the postmodern sublime that is multinational capitalism" (361). Consequently, what Barnett calls for 
are new ways to put the dark and dirty noir-inspired world of cyberpunk back in touch with nowadays' increasing tendencies towards world monopolies that have become a real possibility instead of the culmination of mere imagination. It is such a world that challenges traditional assumptions of selfhood and pushes it towards postmodern fragmentation and decenteredness. And it is cyberpunk with its dangerous dystopian imaginings that is best fit to depict such changes. Yet despite Barnett's call for "resuscitation," such a revival of cyberpunk did not happen until the end of the 1990s when The Matrix (1999), directed by Andy and Larry Wachowski, caused a "resurgence of and improvement on the same cyberpunk aesthetic (only now in visual form)" that "brought a ... smart postmodern aesthetic back to cyberpunk" (Barnett 362).

This "postmodern aesthetic" is influenced heavily by some of the most prominent aspects discussed in postmodern theory. As Veronica Hollinger summarizes: "In virtually every description of 'the postmodern' developed in the past two decades, the increasingly pervasive influence of science and technology on human life has been cited as one of its constitutive features" (232). The consequences of such an augmenting impact eventually lead to a questioning not only of the role of technology in our daily lives, but also of the position humans hold in society. Postmodern theory and art concern themselves with the technological dominance over the human, and cyberpunk takes up a special stance in this context. As Barnett asserts: "[C]yberpunk is the most likely source for answers to questions regarding the machine-human dynamic in multinational society" and "concerns itself most directly with the implications of cyberspace, virtual reality, and a host of technologies that place real human forms at risk of extinction" (360, emphasis in the original).

What cyberpunk does is to show us a world where humans are no longer at the center but where machines have come to take control instead (Barnett 367). Moreover, cyberpunk fiction depicts a world where human subjectivity becomes fragmented as it is no longer grounded in bodily experience. While bodily experience involves interactions of the human body with the physical reality, cyberpunk introduces an interaction between mind and virtual reality in cyberspace. The postmodern present is characterized by simulations, virtual realities, cyberspace and simulacra which no longer require physicality to function. According to Bukatman, we are facing

a postmodern crisis of a body that remains central to the operations of advanced capitalism as sign, while it has become entirely superfluous as object. ... Simply put, the body is not a requisite for the survival of the technocratic system. In cyberpunk science fiction the body finds and occupies a new space; a realm in which a control over the dataspheres of capitalism is restored. Within the intersecting planes of cyberspace, the body is re-placed and subject's autonomy is resurrected. (16, emphasis in the original) 
It is cyberpunk science fiction, and as such also The Matrix, which addresses the implications of this "technocratic system" for its human inhabitant. The film considers the "ontology of cyberspace" (Barnett 360) by taking the viewer into a simulated, digital world where subjectivity can literally be put together out of data fragments. The self is depicted as a construction, and we are in the course of the movie introduced to a subject that no longer needs physicality and unity of self in order to develop a sense of self-identity. Rather, we are presented with a subject whose mind itself becomes embodied and defines itself through agency in an electronic (cyber)space. It is the example of the protagonist Neo that shows us this development, and through him the movie reassures us that even in the Information Age of cyberspace and virtual reality, the human subject will in the end also control this new spatiality.

\section{Mr. Anderson and Reality: Identity and Physical Experience}

Right from the beginning of The Matrix, the viewer gets the feeling that things are not quite normal in this world - our world - as it is presented to him. Although we recognize the tall buildings and rundown streets as any Western city by night and the Agents with their dark suits and radio cables as the standard image of a federal agent, there are some elements in this sequence that throw us off. It is not only the ominous music which accompanies the opening of the first scene through a set of numerical codes on a black screen, but also the following fight and chase sequence of about five minutes where Trinity and the Agent perform movements which seem impossible. Trinity is only later revealed as part of a rebel group that wants to free humanity from the Matrix, the virtual reality they are imprisoned in without their knowledge, while the Agent is introduced as a hunting program encoded into the virtual reality to prevent its destruction. Even with the suspension of disbelief, which the introduction asks us to perform, we are left in the same situation the male protagonist is in when we are introduced to him in the next scene. The setting is recognized as "our world," despite the chase sequence and the greenish filter which gives the shots a gloomy atmosphere, yet there is something odd about it.

Consequently, this first sequence is important in more than one way. It not only presents the technique of "bullet time," which is central to the movie's unprecedented aesthetics, but moreover it leads the viewer to a point where he or she can immediately identify with the protagonist as he is introduced on his search for an answer to explain this strange feeling he has about his world.

In a telling way, the male protagonist is first presented to us as a hacker who goes by the alias Neo, and we get to know him as a person who likes to spend his time in the electronic world of cyberspace. It is this activity which has led him to the ultimate question that Morpheus, the rebel leader and Neo's future mentor, formulates for him: "What is the Matrix?" Yet not long after this encounter, our 
protagonist is revealed to have another identity, which Agent Smith describes as that of "Thomas A. Anderson, program writer for a respectable software company," leading a life in which he is firmly grounded in "reality" - paying taxes, helping an old lady to take out her garbage. Despite his double life, Thomas Anderson's sense of self is clearly bound to a physical experience of the world, even though he often works with computer programs and networks. He is presented to us as someone who uses - or of whom we, up until a certain point, believe he uses - his body to control his actions and, to a degree, his surroundings.

"The self, of course, is embodied" (56) is how Anthony Giddens begins a section on "Body and Self" in his book Modernity and Self-Identity: Self and Society in the Late Modern Age (1991). For Giddens, this section is part of a query into ontological and existential issues that are of importance for a consideration of (post)modern self-identity. Here, he not only describes self-identity as being based on discursiveness (54), but also goes on to discuss the central role of the body for the self in daily life. He specifically links the development of subjectivity to bodily experience: "A child does not learn that it 'has' a body, because self-consciousness emerges through bodily differentiation rather than the other way around" (56). Modern subjectivity, according to Giddens, is built through interaction with the world - meaning both objects and other people (56) - for which one needs a body:

Reality is grasped through day-to-day praxis. The body is thus not simply an 'entity', but is experienced as a practical mode of coping with external situations and events. ... To learn to become a competent agent ... is to be able to exert a continuous, and successful, monitoring of face and body. (56, emphasis in the original)

This is how Neo's identity is shown in this first part of the movie in which he, along with the viewer, does not know that his "reality" is only the Matrix, a virtual reality taking the shape of the world as it was in 1999 and to which every human being is connected. The sense of self that is portrayed here works with the idea that the subject can control his surroundings to a certain degree (follow the rabbit or not, climb out the window or not), but not completely so. The subject is limited by such things as laws of nature and physical constraints - the Thomas Anderson presented to us cannot jump from rooftop to rooftop to avoid the Agents. At least one half of Neo's double life is based on such assumptions. Paying taxes and taking out the landlady's garbage are repeated actions that say something about who Thomas Anderson is since they are results of his agency in a (supposed) reality, a self which he himself constructed.

All this is expressed by what Giddens concludes about the self in his considerations of existential questions: "Self-identity, in other words, is not something that is just given, as a result of the continuities of the individual's action-system, but something that has to be routinely created and sustained in the reflexive activi- 
ties of the individual" (52). Using these assumptions as starting point for the further development of Neo's identity in the course of the movie, I will subsequently focus on the protagonist's loss of a subjectivity based in physicality, and furthermore examine the Construct and its importance for Neo in constructing a new subjectivity.

\section{Uploading and the Construct: Fragmentation and Dislocation of the Subject}

The viewer, just as curious as the protagonist, joins Neo on his path as he sets out to find out what the Matrix is. We share his feelings of disbelief when he - and the audience - finds himself in a world that despite all allusions to Alice in Wonderland and The Wizard of $\mathrm{Oz}$ feels more like an inversion of wonderland than anything else. The distorted camera angles, the pans and tilts shot from Neo's point of view in the cramped space of the Nebuchadnezzar convey a feeling of alienation which we think he must be feeling in this 'real' reality outside the Matrix.

The shock Neo experiences after having been physically and mentally disconnected from the Matrix by the rebels, though, is not only that of learning that his whole life so far has been an illusion, but also the loss of his identity. He was living in a virtual reality without resemblance to the reality that exists outside of it and therefore the control over his seemingly physical surroundings was a lie. He has held no control, no power of agency whatsoever - at least that is what it looks like in the beginning. For someone whose sense of self for his whole life has been based on the idea of physicality and a degree of control over concrete objects, this is a disorienting blow. While this view presupposes a certain measure of physical and geographical unity, these factors are now lost for Neo. About the place where he lived he learns that it does not physically exist at all, and about his concrete surroundings and own body he realizes that they have only been a simulation created by a machine. These realizations result in the "death" of Thomas Anderson that part of his double identity that has been grounded in factors now revealed as non-existent. It is "Neo" who remains because this hacker part of his self has mostly existed in cyberspace anyway. ${ }^{1}$

What follows now in The Matrix is not only a part that shows the training Neo undergoes to be prepared to enter the Matrix as a sort of guerilla fighter, but also a redefinition of his subjectivity which is closely connected to what he learns. Important for this process is what the crew calls "the Construct," a "loading program," as Morpheus explains to Neo when they first enter it after Neo has been disconnected from the Matrix: "We can load anything from clothes, to weapons, to training simulations. Anything we need." Moreover, they can upload parts of

1 This might have to do with the fact that the name "Neo" was chosen by himself. Concerning the relation between the act of naming and identity, see Ravichandran 34-35. 
themselves - or at the least that part which Morpheus calls the "residual selfimage."

The Construct is introduced as a blank space where things can appear and disappear at the will of someone who is controlling the upload from outside. We also get to see it as a Japanese style dojo in which Neo and Morpheus train, as a "jumping program," as a simulation that looks like the Matrix and is filled with rows and rows of weapons. Computer screens inside the hovercraft allow the crew to observe what is happening inside the Construct. It is the operators who control the make-up of the Construct and decide what to load - as Tank, the operator in control of the Construct, tells Neo: "We are supposed to load all these operations programs first, but this is some major boring shit. Why don't we start with something a little fun?" In the Construct, Neo learns all the skills which allow him to survive in the Matrix in his encounters with the Agents. It is in this space where he first shows promise of being someone special when he fights Morpheus.

These points seem to be the basic features of the Construct as far as they are explained in or can be inferred from the movie. Apart from these basic facts, the role of the Construct for Neo's redefinition of subjectivity is hard to point out. In the following paragraphs, I will therefore attempt to examine the Construct's properties within the framework of my argument and to point out possible consequences for Neo's identity.

When entering the Construct, the subject enters an electronic space just as if being plugged into the Matrix since both are computer programs. This process dislocates the subject not only in a geographical sense - because cyberspace is everywhere and nowhere at once - but also concerning a fixed sense of selfidentity. As Bukatman writes:

Subject dislocation is enacted by a movement through an excruciatingly technological, decentering spatiality. The site of origin of the subject passes first outside the body and then inside the terminal. ... [T] he subject is broken down in the zones of cyberspatial simulation, there to await its reconstitution amidst these fields of data. (180, emphasis in the original)

This explanation makes it clear that through subject dislocation, the self is removed from an actual space, such as the one which Thomas Anderson perceives as "reality," in which the body works as the center of agency. Instead, it becomes located in cyberspace where the conditions for the construction of subjectivity are different because cyberspace is not physical and as such denies the self a stable reference point for its identity.

Yet it remains unclear to what extent being in the Construct has different effects on the subject than being in the Matrix. Both are electronic spaces where some outside force determines the subject's surroundings so that the subject can control them only to a certain degree, although this manipulation is different from bodily control in physical reality. The Construct, though, might be different from 
the Matrix in that it is ultimately a human being who is in control of determining the contents of the computer program, not a machine. Because of this it could possibly be considered as a sort of in-between space between the Matrix and physical reality - a humanitarian cyberspace. This idea of a cyberspace in which humans are in control - as in opposition to the Matrix which is controlled by machines - though, is connected strongly to the figure of the operator as someone who delivers the objects and skills necessary for the protagonists to defeat the Agents, and not to the properties of the Construct itself. Any characteristics of human control could be linked back to the fact that the operators, who were born outside the Matrix, are "one hundred percent pure, old-fashioned, home-grown human."

The fact that in the Construct Neo first catches a glimpse of his abilities as the One prophesied to be able to control the Matrix as he wishes, gives this space a degree of importance. Still, the actual impact of the Construct for the refashioning of his identity remains uncertain since it is both similar to the Matrix in its technological properties and different from it as it is controlled by a human.

\section{Plugging Into the Matrix: "Terminal Identity" and the Virtual Subject}

When Neo realizes that what he perceived as "reality" is nothing more than a digitally constructed illusion, he has to come to terms with the fact that his body has never been the center of agency as he thought it was. The only way for him to rebuild a sense of self now lies in creating a routine, a continuity of actions in the way Giddens remarks on the construction of self-identity (52). The Construct, however, with its state in between actual space and cyberspace might give him a first insight into the possibilities of fashioning a new identity for himself. In the following paragraphs, I will examine what impact Neo's entrance into the Matrix has on his sense of self, the relation of his physical and his phenomenological body, and his ability to act.

As Morpheus enters the Construct together with Neo to explain to him how the Matrix works and what reality actually looks like, he describes the way the machines use humans to create energy as "fusion." This kind of combination is usually termed "interface" today, defined as "the boundary of two bodies or spaces," or, as Bukatman writes, "as existing between a body and a space" (192, emphasis in the original). In Terminal Identity, he argues that science fiction presents us with a new form of subject that overcomes this boundary between body and space, or more precisely makes the boundary vanish. By fusing with technology, this new subject becomes able to occupy cyberspace (8-9).

This subject is characterized by what William S. Burroughs calls "terminal identity": "an unmistakably doubled articulation in which we find both the end of the subject and a new subjectivity at the computer station or television screen" 
(Bukatman 9). The terminal identity is the end, the termination, of the sense of subjectivity based on physical reality and geographical unity - the end of the embodied subject Thomas Anderson. On the other hand, this gives rise to the possibility of a subject dislocated from its physical form, one that exists in electronic space, as Neo does in the Matrix.

"Virtual subject" is the term Bukatman uses to define this latter form, "a new subject capable of inhabiting the bewildering and disembodied space of the electronic environment" (118):

$[\mathrm{R}]$ ecent SF frequently posits a reconception of the human and the ability to interface with the new terminal experience - as in cyberpunk - and thus a uniquely terminal space becomes a fundamental part of human (or posthuman) redefinition. ... [W] hat is involved is a projection or transmission of the human into 'the infinite datascape' and the concurrent construction of a spatial simulacrum of the invisible circulation of information. These narratives literalize McLuhan's vision of a prosthetic extension of the human nervous system into the new fields of the electronic environment, granting the process an important spatiality which represents a simultaneous grounding and dislocating of human bodily experience. (118, emphasis in the original)

This projection into cyberspace is what happens to Neo. His consciousness is connected to the technological data spheres of cyberspace, his "residual selfimage" is loaded and supplemented by skills, clothing and other necessities that the operator can digitally create for him. But not everything about this cyberspatial $\mathrm{Neo}$ is the result of data manipulation, since he also possesses his abilities as the One which appear to be inherently his own. He loses his identity as Thomas Anderson but fully inhabits that of "Neo" in the process of (re)constructing his sense of self. His new sense of subjectivity is no longer located in a physical reality and limited by the rules of the system. Instead he understands the fact that what he sees is only an illusion which in the end allows him to at once see the image created by the Matrix and the codes that operate behind it. This makes it possible for him to manipulate the Matrix and thus work against its system.

By entering the electronic space, Neo gains a new sort of experience in that (for him) it is no longer his physical body that "experiences" and connects him to his surroundings and functions as center of his self-identity. Rather, his brain is the new center of his experience as it sorts through the electrical signals sent to it by the electronic system to create a surrounding phenomenal cyber-world: "Virtual reality represents an attempt to eliminate the interface between user and information - by 'transforming data into environment"' (Bukatman 191-92). In a similar fashion, Morpheus asks Neo in The Matrix: "What is real? How do you define real? If you're talking about what you feel, taste, smell or see, then real is simply electrical signals interpreted by your brain." When Neo is plugged into the Matrix and his brain starts constructing an illusion of physical reality from the 
signals it receives, it is these "real" surroundings that allow the mind to become the center of experience.

To be installed into such an apparatus would be to exist on two planes at once: while one's objective body would remain in the real world, one's phenomenal body would be projected into the terminal reality. ... [W]orld and body comprise a continually modifying feedback loop, producing a terminal identity without the terminal - a cybersubject. (Bukatman 187, emphasis in the original)

The screen, which in today's human-machine interface functions as frontier between physical and virtual reality (Bukatman 108), has therefore become nonexistent as border: human and machine merge directly by connecting human nerves to electronic appliances. The construction of a new subject in electronic space creates a new double existence, but not necessarily a double identity, since the sense of subjectivity can be detached from physicality and be connected only to the "phenomenal body," as Bukatman calls it.

For Neo, it thus becomes possible to (re)fashion his new sense of self in electronic spaces such as the Construct and the Matrix, and still retain it even if he is in physical reality. Yet the fact that in order to be able to enter this space he needs to merge with a machine and enter a realm where technology seems to determine his surroundings raises a problem of control. If identity in one of its senses means "an agency," as Ravichandran (6) has pointed out, and according to Giddens (52), the individual's actions are important for creating and retaining it, then it is necessary for the subject to have a certain degree of control which the virtual reality does not offer. In the next section, I will examine this problem in further detail.

\section{Controlling the Matrix: The Question of Agency in Electronic Space}

What The Matrix does is creating for us a visible version of electronic space something that is usually invisible to us. Considering this connection between phenomenology and science fiction, Bukatman writes:

A phenomenology of science fiction helps us to understand the strategies of these works: specifically, their attempt to redefine the imperceptible (and therefore absent to consciousness) realms of the electronic era in terms of the physically and perceptually familiar. The motive is to render the electronic fields present to consciousness - to turn them into phenomena and therefore susceptible to human intention. (117)

The Matrix offers a similar link between seeing and control. Firstly, the language used to talk about the features of the Matrix often revolves around the act of seeing: Trinity tells Neo he has "to see it to believe it," the Agents had their 
"eye on [him] for some time," Morpheus tells him the Matrix is "the world that has been pulled over your eyes to blind you from the truth." Secondly, it is Neo's ability to "simultaneously see the virtual reality of the Matrix, the underlying code that writes and informs it, the bodies that are confined by it, the minds that are controlled by it, and the machines that generate it" (Barnett 369) that characterizes him as the One. Seeing is the sense that is singled out in the movie, and to a certain degree this is because it is a science fiction movie which relies heavily on special effects like bullet time to make visible the electronic space of the Matrix, to show us something we never perceived before. Moreover, the sense of seeing is linked closely with agency, since being conscious of a phenomenon enables us to react to it and, to a degree, shape it as we wish. "The human is inserted into the terminal space as a pure, totalizing, gaze," Bukatman summarizes. "The boundaries of the screen are eradicated, and the cyberscopic field becomes fully phenomenal, susceptible to human vision and action" (136).

With the phenomenological perception of the electronic fields comes a hitherto unseen form of body movement which is only possible in this particular space. What Bukatman says about William Gibson's Neuromancer (1984) in this context is valid for The Matrix as well:

The spatiality of Neuromancer exists to permit bodily mobility and, hence, subject definition. The human becomes the dramatic center, the active agent ... . [T] The phenomenology of perception is transformed into a transcendent valuation of human experience and its 'logical' consequent, human control. (206)

Mobility and perception, the two aspects of subjectivity named here, are according to Bukatman usually connected to a lived-body (207), but here they become characteristics of the "phenomenal body" of electronic space, the body-image generated by the mind, or the "residual self-image, the mental projection of your electronic self," as it is called in The Matrix. This becomes the reason why the simultaneous existence on two levels as experienced by someone who enters the Matrix is meaningless for subject definition. As Bukatman explains: "Thus, the duality between mind and body is superseded in a new formation that presents the mind as itself embodied. The body, here, exists only in phenomenological terms: it perceives and it moves" (208, emphasis in the original). The fact that the mind is detached from the physical body is presented as a gain of strength for the subject in the movie: not only does the phenomenal body in the Matrix offer a range of movements which would not be possible with one's actual body, but in this space Neo eventually acquires, in Morpheus's terms, the ability to "change what he wanted, to remake the Matrix as he saw fit," he has absolute control.

While such an obsolescence of the physical body is sometimes considered as the ultimate form of the death of the subject (as e.g. in Barnett 369), The Matrix instead presents it as the ultimate empowering of the subject. The new strength 
and power of agency gained by entering the virtual reality of the Matrix serve as elements for constructing a new sense of subjectivity in that they allow for the subject's control over its actions. Although this is only achieved through a merging of the human with technology, it is the human, i.e. Neo, who comes out on top in this fusion. ${ }^{2}$ Thus, despite the movie's celebration of the connection between human and technology and the body's devaluation, it still carries an affirmation of human agency and even supremacy. Therefore, it is also necessary that $\mathrm{Neo}$ is revealed as the One.

Neo is the center of the audience's focus during The Matrix's progression. This is not only because he is the protagonist, but mostly due to the fact that he is the one the viewer can best connect to since he is the only crew member to go through the painstaking process of revelation, alienation and redetermination of who he is in a new, strange world. He is the Alice or Dorothy we follow to accommodate to the unfamiliar wonderland we have been thrust into right alongside him.

Furthermore, he is also the only member of the crew to eventually completely master the Matrix, the only one with ultimate control over the spatiality of this virtual reality. With this development, the movie reassures us that even in a time when technology becomes more and more important and the interface between human and machine becomes more and more blurred and malleable, the human will be the one to come out on top. He will be the master of technology in the end, even though in the beginning it seemed to be the machines that had humanity completely subdued and mastered.

Only by establishing Neo as the powerful figure of the One can The Matrix offer an empowered version of the human mind, one that does not even need a body anymore to achieve agency. With this elevation of the mind, the movie solves the problem of identity that has been raised with the simultaneous obsolescence of the human body and the human self-identity based on geographic unity, mobility and agency that presupposes bodily control. All this, though, is only possible as long as Neo is the One who has the power to "remake the Matrix as he saw fit," for otherwise he would only be another victim of the machines' power so that the movie's message about the future of the human subject would be a pessimistic one instead. By allowing Neo to assume the role of the One, though, the movie follows a cyberpunk tradition of an empowering dissolution of the body (Bukatman 21) that simultaneously elevates the status of the non-physical mind.

2 For an analysis on similar instances in written science fiction, see Bukatman 208. 


\section{Works Cited}

Barnett, P. Chad. "Reviving Cyberpunk: (Re)Constructing the Subject and Mapping Cyberspace in the Wachowski Brothers' Film The Matrix." Extrapolation 41.4 (2000): 359-74. Print.

Bould, Mark. "Cyberpunk." A Companion to Science Fiction. Ed. David Seed. Malden, MA: Blackwell, 2005. 217-31. Print.

Bukatman, Scott. Terminal Identity: The Virtual Subject in Postmodern Science Fiction. Durham, NC: Duke UP, 1993. Print.

Giddens, Anthony. Modernity and Self-Identity: Self and Society in the Late Modern Age. Cambridge: Polity P, 1991. Print.

Hollinger, Veronica. "Science Fiction and Postmodernism." A Companion to Science Fiction. Ed. David Seed. Malden, MA: Blackwell, 2005. 232-47. Print.

Landon, Brooks. The Aesthetics of Ambivalence: Rethinking Science Fiction Film in the Age of Electronic (Re)Production. Westport, CO: Greenwood Press, 1992. Print.

Ravichandran, T. Postmodern Identity. Jaipur: RBSA Publishers, 2007. Print.

The Matrix. Dir. Andy Wachowski and Larry Wachowski. Perf. Keanu Reeves, Laurence Fishburne, and Carrie-Anne Moss. Warner Home Video, 1999. DVD. 